\title{
Génesis de la estructura arqueada de la Sierra de las Cabras al Gibalto (Subbético, provincias de Málaga y Granada, España)
}

\author{
Genesis of the Las Cabras to the Gibalto arched structure (Subbetic, \\ Malaga and Granada provinces, Spain)
}

\author{
C. Sanz de Galdeano ${ }^{1}$
}

\section{RESUMEN}

\begin{abstract}
Las sierras subbéticas de las Cabras al Gibalto forman una estructura arqueada, que da un fuerte relieve, constituida por escamas tectónicas, vergentes al sur en su borde convexo, meridional, y al norte y oeste en su borde cóncavo. Aunque podría interpretarse como una estructura alóctona, se encuentra enraizada en el área de tránsito entre el Subbético Medio y el Interno. En su génesis han influido varios factores locales pero la causa que controla a todos ellos es la colisión oblicua, en transpresión, de la Zona Interna Bética contra la Externa, que produjo un importante sistema de desgarre.
\end{abstract}

Palabras clave: Cordillera Bética, Subbético, contacto Zona Interna -Zona Externa, transpresión.

\begin{abstract}
The Subbetic sierras of Las Cabras to the Gibalto form an arched structure, giving it a high relief, constituted by many tectonic slices, verging to the South in its southern border and to the North and West in its concave border. Although it could be interpreted as an allochthonous structure, really is rooted in the transitional area between the Median and the Internal Subbetic. Several local factors have influenced this complex structure, but the final cause is the oblique collision (transpression) of the Internal Zone against External Zone of the Betic Chain, producing an important strike-slip system.
\end{abstract}

Key words: Betic Cordillera, Subbetic, Betic Internal-External zones contact, transpression.

\section{Introducción}

La Cordillera Bética está formada, como muchos otros orógenos, por dos grandes conjuntos o zonas. Hacia el norte se encuentra la Zona Externa, dividida en Subbético y Prebético, este último dominio situado más próximo a la Meseta española y al borde S y SE de la Cordillera Ibérica. Las series estratigráficas de ambos dominios tienen edades que abarcan del Trías al Terciario. La Zona Interna está formada por cuatro complejos superpuestos tectónicamente que de abajo arriba son: NevadoFilábride, Alpujárride, Maláguide y Dorsal. Los tres primeros complejos tienen términos del Precámbrico al Mesozoico e incluso del Terciario, mientras que la Dorsal tan solo del Mesozoico en adelante. Los dos primeros complejos han sufrido metamorfismo alpino, lo que no es el caso del Maláguide y la Dorsal. Estos dos últimos complejos están muy ligados entre sí, siendo el sector más interno de la Dorsal una parte de la cobertera del Maláguide. Además de estas zonas, también existen en las Béticas las unidades de los Flyschs y las cuencas neógenas, estas últimas en muchos puntos depositadas sobre cualquiera de los anteriores dominios geológicos (Sanz de Galdeano y Vera, 1992).

La colisión oblicua de la Zona Interna con la Externa produjo, sobre todo en esta última, una enorme deformación (Andrieux et al. 1971; Durand Delga y Fontboté, 1980; Wildi, 1983; Martín Alga-

\footnotetext{
1 Instituto Andaluz de Ciencias de la Tierra (CSIC-Univ. Granada). Email: csanz@ugr.es
} 


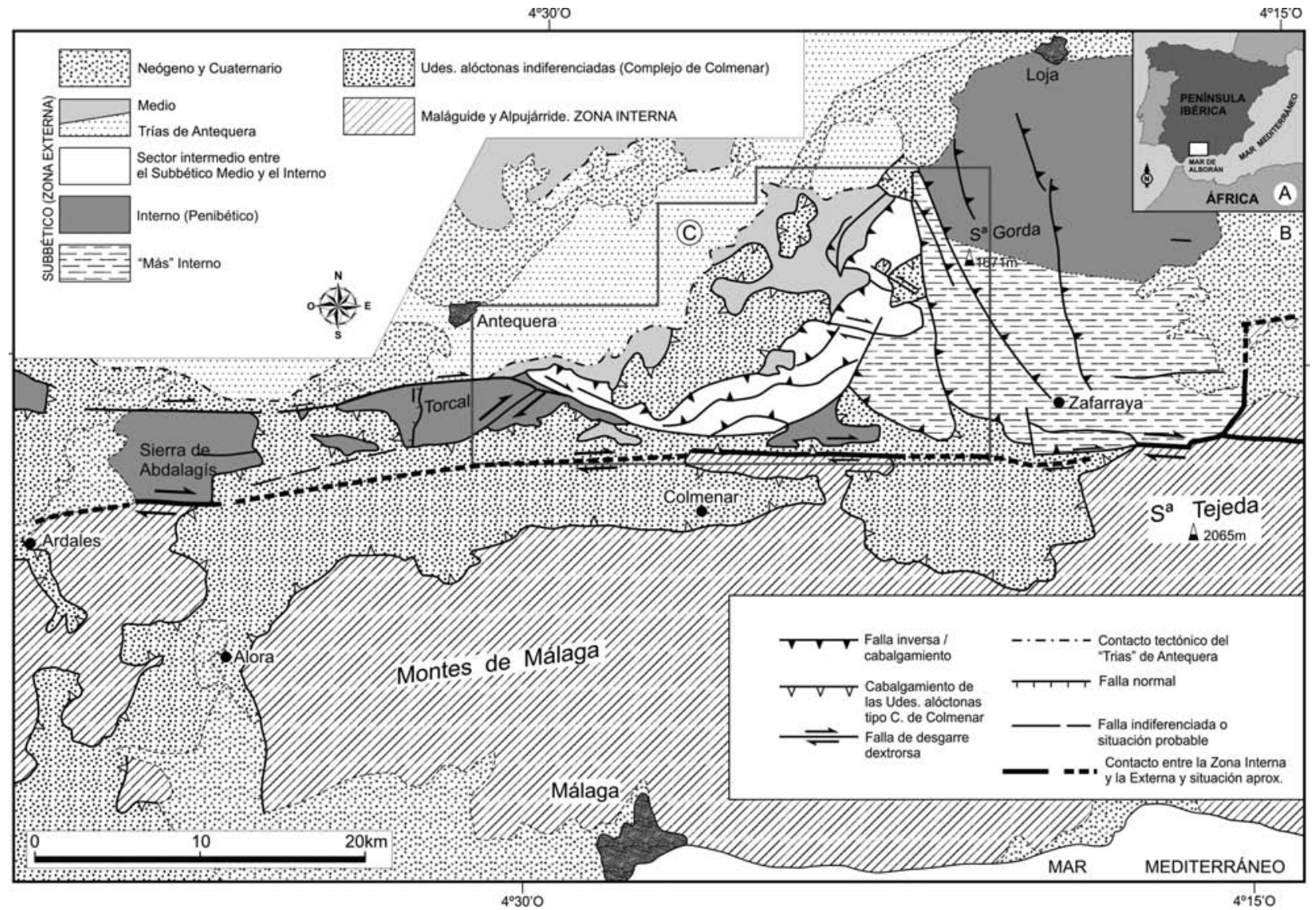

Figura 1.-Situación del área estudiada. A: Localización dentro de la península lbérica. B: Entorno geológico en el que se encuentra el área estudiada (C, polígono correspondiente a la figura 2 ).

rra, 1987; Sanz de Galdeano 1990 y 1996, etc). Esta colisión ocurrió en el Mioceno inferior, particularmente durante el Burdigaliense (paroxismo Burdigaliense de Hermes, 1985), amortiguándose las deformaciones a lo largo del Mioceno medio. La cuenca original subbética quedó destrozada y se formaron numerosas unidades tectónicas en la Zona Externa que generalmente se desplazaron hacia el $\mathrm{NO}$ y al ONO. De entre esas unidades destaca un enorme olistostroma que fue expulsado hacia la cuenca del Guadalquivir y el Golfo de Cádiz. Su evolución se prolongó incluso durante parte del Mioceno superior. La citada colisión tuvo carácter transpresivo, dado que la Zona Interna venía expulsada desde el E (Durand-Delga y Fontboté, 1980; Wildi, 1983; Martín Algarra, 1987; Sanz de Galdeano, 1990, etc.) y colisionó lateralmente con el Subbético, produciéndole, además de las deformaciones señaladas, notables rotaciones horarias en buena parte de las unidades entonces formadas.
En el área estudiada (Figs. 1 y 2) afloran los siguientes elementos: el Subbético, ampliamente representado; el Maláguide, localizado al sur, y sobre ambos y entre ambos, las unidades del complejo de Colmenar (Vera, 1969) que grosso modo se pueden asimilar a las unidades de los Flyschs. Esta área forma un arco montañoso de relieve escarpado, constituido por una sucesión de sierras en cuyos extremos se encuentran la de Las Cabras al oeste, y la del Gibalto al este (en adelante, será referido como arco Cabras-Gibalto). Este relieve domina claramente al existente al norte y al sur, si bien, al este la mole de Sierra Gorda de Loja es de mayor altura localmente y mucho mayor volumen. Al oeste, se sitúa el Torcal de Antequera que tiene su propia individualidad.

El primer autor que estudió la región fue Blumenthal (1931), quien, aunque no contó con mapas modernos ni imágenes aéreas realizó excelentes observaciones. Llegó a plantearse si el arco Cabras- 


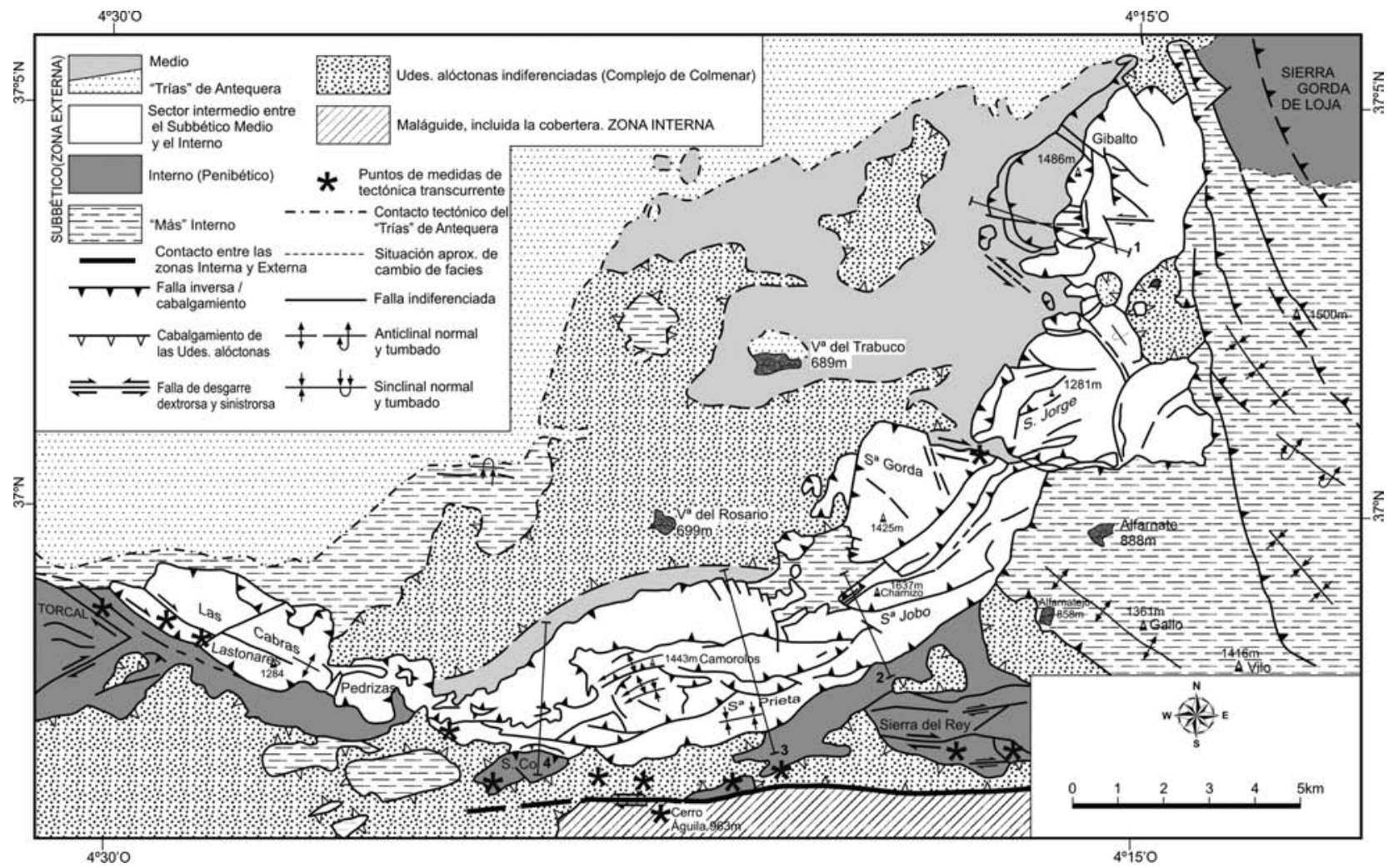

Figura 2.-Esquema geológico del arco de la Sierra de las Cabras al Gibalto. Su posición se indica en la figura 1. Los asteriscos indican puntos donde se observan claros rasgos de tectónica transcurrente dextrorsa. Se señalan las posiciones de los cortes de la figura 3.

Gibalto es completamente alóctono o se enraíza en el área en que se encuentra, pareciendo inclinarse finalmente por la primera posibilidad citada. No contaba con datos paleogeográficos que le habrían ayudado.

Mucho más adelante, Vera (1969) describió las series y los rasgos generales del área de Sierra Gorda, de la Sierra de Enmedio (muchas veces llamada de Gallo-Vilo en alusión a sus dos picos principales) y de Zafarraya, situada al este. Al tiempo, Magné et al. (1969) describieron la Sierra de GalloVilo y en la cartografía presentada mostraron que está cabalgada por el arco Cabras-Gibalto, menos en un sector que dejan indefinido.

Peyre (1974), estudió el arco Cabras-Gibalto entre otros sectores y lo denominó Haut Chaîne, Alta Cadena, en alusión a su fuerte relieve (es mejor evitar dicho término pues, salvo en un restringido ámbito geológico, estas sierras no son conocidas así). El estudio de este autor es bastante detallado y preciso en los aspectos estratigráficos, si bien no llegó a abordar en profundidad la génesis de la estructura.
Barba-Martín et al. (1979), Delgado y Sanz de Galdeano (1981) y Pineda (1983 y 1987) realizan la cartografía del sector, sentando las bases para una interpretación general de la génesis de la estructura. También aportan datos estratigráficos y tectónicos los trabajos de Martín Algarra (1987) y Serrano y Guerra-Merchán (2004).

Más adelante, Balanyá et al. (2008) publicaron aspectos tectónicos de lo que llamaron Alta Cadena, pero en este caso comprendiendo desde el oeste la Sierra de Abdalajís - o de Huma- hasta la Sierra de las Cabras incluida, pero no el resto del arco CabrasGibalto (no abarca la misma área que corresponde a la Alta Cadena de Peyre, 1974). Estos autores destacan que la tectónica del área estudiada se puede comprender "como una zona de deformación transpresiva con sentido de cizallamiento dextro".

Crespo-Blanc (2008) hizo un modelo analógico en el que encontró claras similitudes entre las estructuras oblicuas desarrolladas en el ensayo con las existentes en el Subbético, incluida el área estudiada en el presente artículo. 
Sanz de Galdeano (1996) hizo una interpretación general del significado de los corredores E-O de la Zona Interna Bética y su repercusión y continuación, en su caso, en la Zona Externa. Es un trabajo que ahora se pretende completar para el sector del arco Cabras-Gibalto con datos más precisos.

Por ello, el objetivo del presente artículo más que la descripción de la estructura del arco CabrasGibalto, en general bastante bien conocida pero a la que se aportan nuevos datos, es discutir su génesis, apoyándose en dicha estructura, en la paleogeografía y en nuevos datos tectónicos.

\section{Principales rasgos geológicos del sector estudiado}

Los materiales que forman el arco Cabras-Gibalto corresponden al Subbético y dentro de éste al Subbético Medio, al paso del Medio al Interno, al Subbético Interno o Penibético y a un dominio que llamamos simplemente "Más Interno", con el fin de evitar connotaciones paleogeográficas complejas (los rasgos generales de esta división fueron introducidos por García-Dueñas, 1967 y 1969, y se basan en diferencias en el tipo y desarrollo de los sedimentos jurásicos). En general, todos los distintos dominios subbéticos presentan dolomías y calizas del Lías inferior, y a partir de ese momento se formaron sectores diferenciados, unos más subsidentes y otros más someros. En el Subbético Medio, a partir de finales del Lías inferior, se dio un importante desarrollo de margas y radiolaritas que llegan incluso al Malm, el cual suele acabar generalmente con margocalizas y calizas (nodulosas o no). Por su parte, en el Interno siguió el desarrollo de calizas, particularmente calizas nodulosas en el Malm. El Subbético Medio corresponde a un surco dentro de la primitiva cuenca subbética, mientras que el Interno quedó en un umbral.

La mayoría de las unidades tectónicas del arco Cabras-Gibalto se sitúan en el tránsito entre los dominios subbéticos Medio e Interno. Dependiendo de las unidades y de los puntos que se traten -hay continuos cambios laterales de facies- el desarrollo de margas y radiolaritas es mayor o menor. En general las series de las unidades de esta área de tránsito son bastante reducidas y son más afines a las del Subbético Interno. Este dominio intermedio paleogeográficamente debió estar afectado por fallas profundas por donde salieron numerosas rocas volcánicas, situadas en materiales del Triásico y del Lías.
Tampoco el Subbético Interno o Penibético es constante en sus facies. Ya se ha indicado su cambio hacia el Subbético Medio y ahora se indica que también lo hace hacia áreas actualmente más meridionales, sobre todo hacia el SE. Esto se ve bien en Sierra Gorda de Loja, donde a partir de un cierto paralelo -en la posición actual- (Figs. 1 y 2) comienzan a intercalarse margocalizas y margas, después radiolaritas, etc. que indican la existencia de un surco subbético en posición más meridional, más interna. En algún caso separar las series de este Subbético "Más Interno" del Subbético Medio sería algo imposible, aunque se puede hacer por su distinta posición tectónica y por los tránsitos observables. Se utiliza para este surco el término "Más Interno" para evitar nombres como citra o ultrabético, que pueden dar problemas con sus significados de "del lado de aquí" o "más alejados". Quede la idea del paso progresivo hacia un subbético más interno, sin significar al tiempo que ese surco fuera homogéneo.

Al NO del arco Cabras-Gibalto se encuentra el "Trías de Antequera", descrito por Peyre (1974) y entrecomillado por Sanz de Galdeano et al. (2008) debido a que contiene en no pocos puntos materiales del resto del Mesozoico y del Terciario, algunos de ellos con un ligero metamorfismo, y que ha formado una importante "mélange" tectónica, a la vez que un gran olistostroma (que se une al enorme olistostroma subbético - Pérez López y Sanz de Galdeano, 1994). Este "Trías" originariamente se enraizó bajo el Subbético Medio y en parte quizás en el tránsito hacia el Interno (Sanz de Galdeano et al., 2008).

Al sur del arco Cabras-Gibalto se encuentra la Zona Interna, en este sector representada por el Maláguide, formado sobre todo por materiales paleozoicos y más antiguos.

Las unidades de los Flyschs (complejo de Colmenar, véanse las Figs. 1 y 2) cabalgan tanto la Zona Interna como la Externa. Se sitúan sobre ambas zonas y son complejas en su estructura y procedencia, pero tienen la virtud de comportarse en conjunto como una cobertera, aunque localmente afectada por la tectónica del arco Cabras-Gibalto y de la Zona Interna.

Otros materiales corresponden a sedimentos neógenos y cuaternarios, discordantes sobre los anteriores. Los del Mioceno superior, de carácter marino somero, localmente situados a alturas del orden de $1000 \mathrm{~m}$, revelan el importante levantamiento ocurrido desde su depósito. 


\section{Estructura del arco subbético de las Cabras al Gibalto}

El principal rasgo de la estructura del arco es su escamación en un gran número de unidades tectónicas (Figs. 2 a 4 ).

En la parte occidental y central del arco la mayor parte de las escamas son de vergencia al sur, hacia la Zona Interna, mientras que en el borde norte del arco la vergencia es al norte. Existen algunas escamas que vergen en sentido contrario, tal como el cabalgamiento de la Sierra del Co (del Codo en algunos mapas y en Blumenthal, 1931), donde el Subbético Interno cabalga a las unidades de carácter intermedio entre el Interno y el Medio. Pero por lo general no ocurre así y son esas unidades "intermedias" las que lo hacen sobre el Interno.

En la parte oriental del arco la vergencia predominante es hacia el oeste. En la propia Sierra Gorda de Loja hay fallas inversas, que buzan del orden de 50 grados, que muestran el transporte tectónico que han sufrido, hacia el oeste, las escamas que constituyen dicha sierra. Ya en el extremo oriental del arco, el Gibalto (Fig. 3, corte 1 y Fig. 4, A) está formado por escamas del Subbético Medio y del sector intermedio entre el Subbético Medio y el Interno, que, salvo en un punto, son todas de vergencia al oeste.

Existe un sector de tránsito de las vergencias en este arco. Así, del Chamizo hacia el oeste, todo el borde sur del arco tiene vergencia al sur (Figs. 2 y 3). Las escamas allí existentes, del sector de tránsito entre el Subbético Medio y el Interno, suelen cabalgar a este último, con la excepción señalada de la Sierra del Co. Desde el Chamizo hacia el norte, las escamas comienzan a verticalizarse, de manera que llegan a invertirse los cabalgamientos originalmente hacia el sur (Fig. 4, B y C).

El borde interno, cóncavo, del arco ya se ha señalado que siempre cabalga hacia el norte o al oeste. En muchos puntos el cabalgamiento buza del orden de 50 a 70 grados, aunque es menor en otros, por ejemplo en algunas escamas del Gibalto y también en el sector del puerto de las Pedrizas, por donde atraviesa la autovía de Málaga-Granada. También hay algunos isleos flotantes, cuya base es prácticamente horizontal. Localmente este cabalgamiento pinza a las unidades de los Flyschs o del Complejo de Colmenar.

Dado que el arco Cabras-Gibalto cabalga tanto al norte como al sur puede pensarse que es completamente alóctono y sin conexión directa con los dominios paleogeográficos en los que se encuentra.
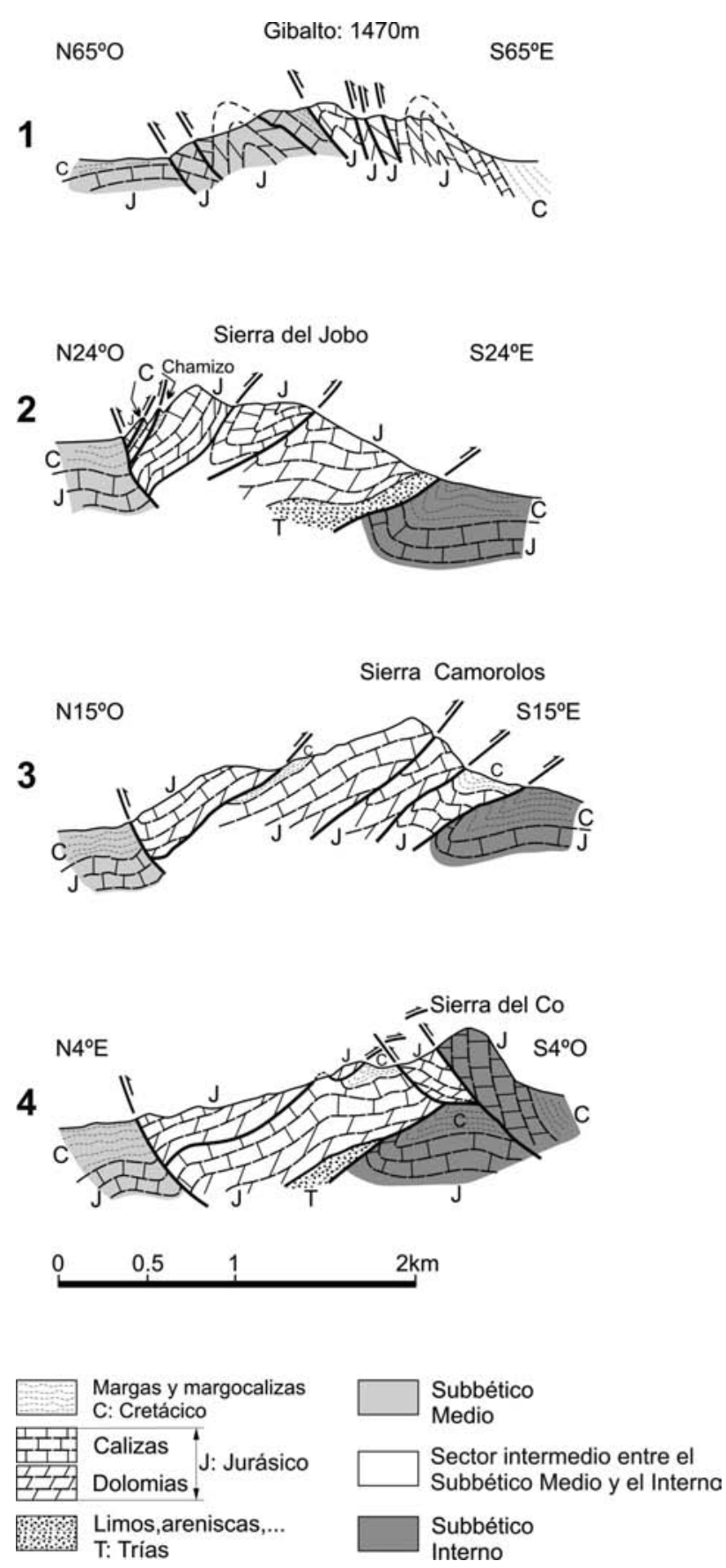

Figura 3.-Cortes geológicos del arco Cabras-Gibalto. Se puede observar bien la tectónica de escamas y la diferente atribución paleogeográfica de los bordes del arco. La posición de los cortes se señala en la figura 2 . El corte 1 se ha simplificado de Delgado y Sanz de Galdeano (1981).

Pero también cabe pensar que se encuentre enraizado y por tanto in situ, manteniendo en general las relaciones paleogeográficas originales con respecto a su entorno dentro del Subbético. 

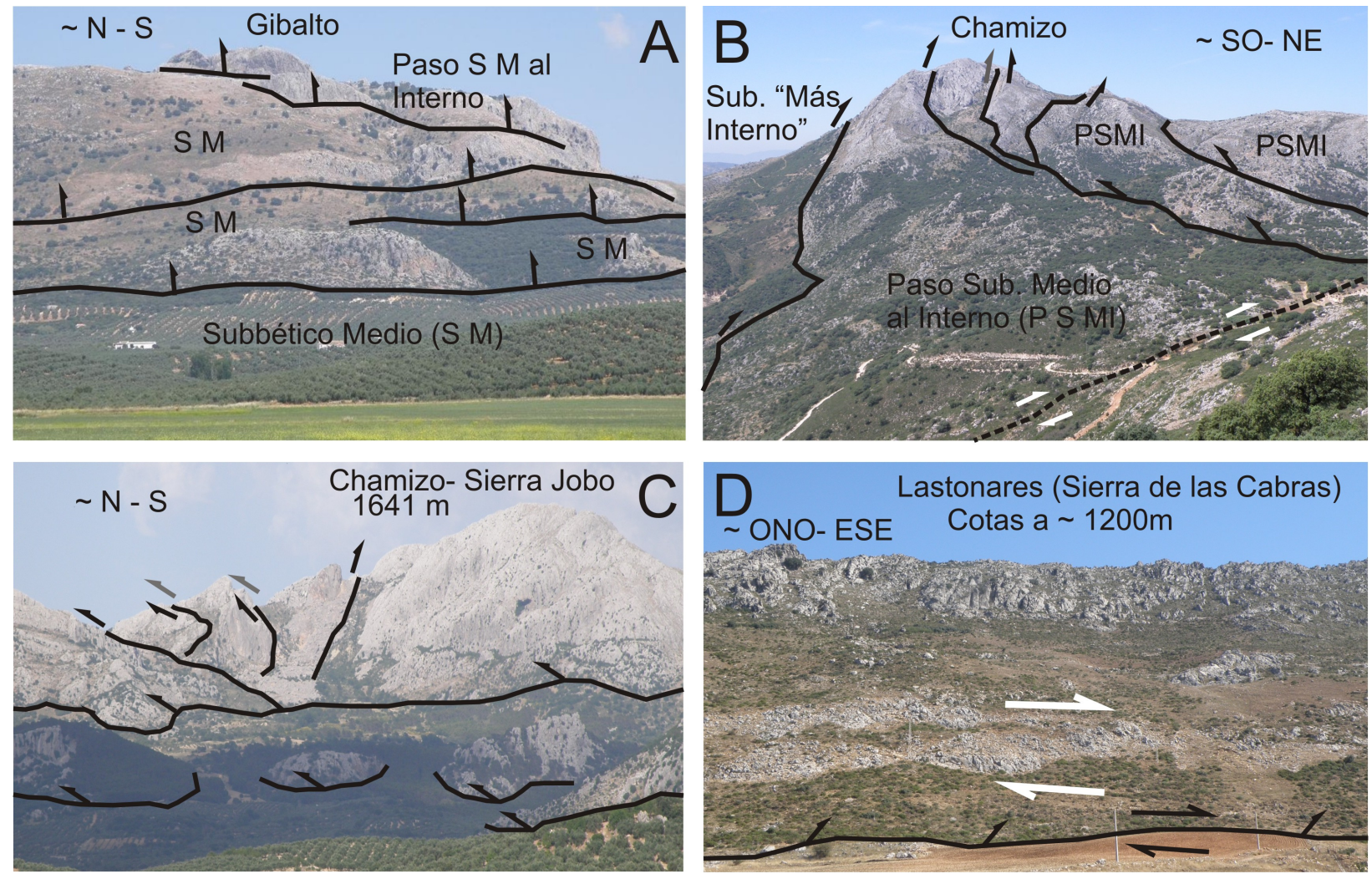

Figura 4.-A: Escamación tectónica en el borde occidental del Gibalto. B: Vista de las escamas tectónicas de la parte norte del Chamizo (Sierra del Jobo). A la izquierda puede observarse la inversión del cabalgamiento originalmente hacia el S y SE. A trazos se indica parte de la falla dextrorsa del E de Villanueva del Trabuco en su sector menos espectacular. C: Vista del borde occidental del Chamizo - Sierra del Jobo. Se señalan también las escamas con su dirección de desplazamiento. Las flechas grises (en B y C) indican movimientos aparentes resultantes tras la inversión de las escamas. D: Parte sur del borde occidental de la Sierra de las Cabras en el que se ven diversos cuerpos sigmoidales formados en calizas del Lías inferior congruentes con el movimiento transcurrente dextrorso de ese sector.

Si se observa la posición del arco Cabras-Gibalto en las figuras 1 a 3 es claro que las unidades que lo forman se sitúan entre el Subbético Medio y el Interno (o el "Más Interno" en la parte oriental). A su vez, su estratigrafía marca igualmente una posición intermedia con respecto a la de las unidades situadas al norte y sur del arco. Por ello, el conjunto de datos disponibles llevan a la interpretación de que el arco se enraiza donde está, aunque se encuentre muy fracturado y dividido en numerosas escamas y, dado el enorme grado de apretamiento sufrido, ha cabalgado al sur y al norte, y en la parte oriental al oeste, existiendo una zona de tránsito.

Esta es la interpretación general que se propone para el arco Cabras-Gibalto, pero, aun así, existen algunos puntos, particularmente en el sector de las Pedrizas, y hasta unos $4 \mathrm{~km}$ al este, donde persiste una duda que pensamos irresoluble sobre la atribución de la procedencia de alguna escama. Es decir, en alguna escama inferior no sabemos si estamos ante una unidad que pertenece paleogeográficamente al Subbético Medio o al Intermedio. Es que se observan cabalgamientos de dolomías del Lías inferior sobre calizas, también del Lías inferior, y a esos niveles no es posible, por lo menos para el autor, distinguir entre la procedencia de las unidades. Cabe por tanto que, al igual que en el Gibalto, en el sector de Las Pedrizas, también se encuentre directamente concernido el Subbético Medio.

\section{Algunos datos de estructuras que informan sobre la cinemática de los movimientos de varios sectores del arco Cabras-Gibalto}

La cartografía de la multitud de escamas y otras estructuras que conforman el arco generalmente es muy fácil de hacer pues el contraste litológico exis- 
tente permite su diferenciación, aunque hay puntos donde no es sencilla al ponerse en contacto tectónico similares tipos de rocas, generalmente calizas o dolomías. Sin embargo, la observación de estructuras menores ligadas a las escamas está dificultada por la formación de suelos y el largo tiempo de exposición de los afloramientos. Pero en algunos puntos se conservan bien.

Uno de ellos corresponde a la falla dextrorsa que corta y desplaza la Sierra de San Jorge de la Sierra Gorda de Villanueva del Trabuco (Fig. 2 y Fig. 4, B). El desplazamiento es del orden de $3 \mathrm{~km}$. La superficie de esta falla se observa bien en la pista que desde esa localidad asciende a las sierras. Es un plano casi vertical con estrías próximas a la horizontal. En la zona de falla se observan, muy brechificados, materiales del Trías al Terciario (estos últimos del complejo de Colmenar). Las superficies de falla se desarrollan bien en calizas jurásicas. Además, pequeñas y muy abundantes fallas se observan bien en sedimentos del Cretácico superior. En esa misma falla, hacia el este, existen grandes "almendras" - enormes cuerpos sigmoidales-, del orden de la centena de metros, de calizas jurásicas, formadas por efecto del desgarre. Esta falla es una estructura que corta netamente a las escamas.

Además de las estructuras menores de esa falla, el estudio de las del borde sur del arco muestra rasgos interesantes. Se describen de oeste a este:

- En el sector más occidental del arco, en la terminación de la Sierra de las Cabras, área de la Boca del Asno - puerto situado al este del Torcal de Antequera - se ven estructuras ligadas a un importante desgarre dextrorso. Así, en la carretera que bordea el Torcal hay escarpes de falla con estrías cuyo rake varía entre cero y unos 80 grados, siempre con componente dextrorso. Estrías con unos 25-30 grados de rake son las más abundantes. Estos escarpes se sitúan en el borde del Torcal.

Muy cerca, pero en el borde de la Sierra de las Cabras, lo que se observa son cuerpos sigmoidales (en la Fig. 4, D se observan algunos de ellos) formados en calizas liásicas situadas sobre dolomías. Estas calizas se adelgazan mucho hacia el SE donde existen unos cortados naturales (en el área que llaman Lastonares) que son fallas próximas a la vertical, longitudinales a la sierra, con estrías predominantemente horizontales o casi, también dextrorsas. Estas estructuras de la Boca del Asno documentan bien que el contacto entre el arco Cabras-Gibalto y el Torcal es a través de una importante falla de desgarre (Figs. 1 y 2).

Más al este, localmente, así en las Pedrizas, en parte en los frentes de las escamas más meridionales, se ven estructuras menores que corresponden a estriaciones horizontales, dextrorsas y dispuestas longitudinalmente con respecto al arco. Uno de los puntos donde esto se observa mejor es en el borde SO de la Sierra del Co, en su corte con la carretera. Allí existen diversos desgarres que muestran bien un neto movimiento dextrorso del borde sur de esta macroestructura arqueada.

En el mismo borde sur del arco Cabras-Gibalto, los derrubios tapan los contactos, pero algunas pistas permiten buenas observaciones inmediatamente al sur (asteriscos en Fig. 2). Se observan pequeñas fallas verticales o casi, de dirección cercana a E-O, con estrías prácticamente horizontales, dextrorsas, formadas en sedimentos del Cretácico inferior y superior, en áreas muy cercanas a la Zona Interna, Maláguide. Incluso el propio Maláguide, en el Cerro del Águila, se encuentra netamente afectado por fallas de las mismas características, localmente con planos muy bien formados, que muestran la misma tectónica transcurrente dextrorsa.

Al este del Cerro del Águila estructuras de este tipo se observan en sedimentos del Cretácico superior y también en calizas jurásicas del Subbético Interno. En este sector los rasgos de transcurrencia dextrorsa en una dirección aproximada E-O son muy abundantes. Sin embargo, hay que hacer notar que en algunos puntos, en sedimentos del Cretácico superior, también hay rasgos de desplazamientos en la dirección $\mathrm{N}-\mathrm{S}$ con vergencias en los dos sentidos.

\section{Interpretación de la génesis de la estructura del arco Cabras-Gibalto}

Aunque la macroestructura arqueada presenta cabalgamientos hacia el exterior, sobre todo al sur, sus bordes no son equivalentes. Por ello, la hipótesis que podría ser más simple, la que interpretaría que el arco está simplemente cabalgante sobre el resto del Subbético sin que se supiera de dónde venía, no es la más aceptable. El hecho de que al norte se sitúe el Subbético Medio y al sur el Interno o el "Más Interno" y que el propio arco en sí, esté formado por unidades de carácter intermedio entre el Medio y el Interno lleva a la conclusión de que está enraizado y no es totalmente alóctono. 
En la formación del arco fue determinante la colisión oblicua de la Zona Interna con respecto a la Externa. Buena parte del Subbético Interno (y del dominio aún "Más Interno") fue desplazada hacia el oeste a la vez que sectores del Subbético Medio (y del sector intermedio entre el Subbético Medio y el Interno presente en el arco) quedaban rezagados, de manera que en relación con el Interno se movían hacia el este. Los desgarres mostrados en la Zona Interna y en el borde sur del arco Cabras-Gibalto, comenzando por la Boca del Asno corresponden a estos movimientos relativos. Igualmente, las estructuras que muestran la transcurrencia dextrorsa al sur del arco, incluso en la Zona Interna, muestran el contexto transpresivo en el que se desarrollaron.

En este proceso, el actual sector de CabrasGibalto sufrió una fuerte compresión lo que produjo su importante escamación hacia el sur e incluso el comienzo de expulsión también hacia el norte. Esto se vio ayudado además por el diapirismo tectónico que sufrió el "Trías de Antequera" que fue localmente fuertemente pinzado (también por el mismo proceso de colisión oblicua entre la Zona Interna y la Externa), lo suficiente para que en algunos de sus materiales se produjera un epimetamorfismo claramente visible (Sanz de Galdeano et al., 2008). Este "Trías" saliendo sobre todo hacia el norte, pero también hacia el sur, contribuyó al empuje que se manifiesta en el arco CabrasGibalto.

A la vez contribuyó otro factor: el contacto entre la Zona Interna y la Externa no es rectilíneo ni uniforme en la Cordillera sino que tiene irregularidades, escalones, uno de los cuales se sitúa al SE de Sierra Gorda de Loja (Fig. 1). El área de la Sierra Gorda de Loja fue un sector de curvatura contractiva (restraining bend) dentro del contacto tectónico entre las zonas Interna y Externa. Esto hizo que los materiales que actualmente forman dicha sierra se vieran fuertemente empujados hacia el oeste, formándose pliegues e importantes fallas inversas vergentes al oeste. Esta enorme masa, y otra menor, la del Gallo-Vilo, empujaron el borde oriental del arco, girándolo y provocando la vergencia al oeste del sector del Gibalto. En ese choque, las unidades que forman el Gibalto fueron las que sufrieron el mayor desplazamiento tectónico hacia el oeste; en menor grado lo fue la Sierra Gorda de Villanueva del Trabuco y la Sierra de San Jorge lo fue aun menos, rezagándose y formándose entonces la falla de desgarre antes citada.
En su conjunto, el motor esencial de la formación del arco Cabras-Gibalto se encuentra en la colisión oblicua de la Zona Interna con la Externa en su traslación hacia el oeste. Esto produjo arrastres importantes en el Subbético formándose una zona de cizalla dextrorsa entre la Zona Interna y el Subbético y dentro del Subbético sobre todo entre el Interno y el Medio. En esta zona de cizalla, el área ahora correspondiente al arco quedó fuertemente deformada, con la enorme masa de Sierra Gorda de Loja comprimiendo su borde oriental y configurando la forma de arco. Esta interpretación general viene avalada por la obtenida por Crespo (2008) a partir del modelo analógico que realizó.

\section{Conclusiones}

Las escamas tectónicas del arco de las sierras de las Cabras al Gibalto cabalgan al sur y al norte, lo que le da apariencia de ser completamente alóctono con respecto a los sectores del Subbético sobre los que se sitúa. Sin embargo, el hecho de que los bordes no sean equivalentes paleogeográficamente (el borde norte está ocupado por el Subbético Medio, mientras que el sur lo está por el Subbético Interno) y que la estratigrafía de las escamas muestren un carácter intermedio entre ambos dominios, indican su posición "in situ" y que se enraiza en el sector en el que se encuentra.

La génesis del arco se ha producido gracias a un conjunto complejo de factores, tales como el enorme acortamiento que sufrió, el desplazamiento hacia el oeste de la mole de Sierra Gorda de Loja, y el del "Trías de Antequera" hacia el sur y la actuación del sistema de desgarre existente entre el área del Torcal y el propio arco. Pero todos estos factores "locales" fueron activados y controlados por la colisión oblicua de la Zona Interna con la Externa, que es la causa primera de las deformaciones del Subbético en este sector.

\section{AGRADECIMIENTOS}

Este estudio se ha hecho gracias a los proyectos del Ministerio de Ciencia e Innovación: CGL2007-60535, TOPO-IBERIA CONSOLIDER-INGENIO (CSD2006-00041) y P06RNM01521 y del grupo de Investigación RNM- 370 de la Junta de Andalucía. A. Caballero delineó las figuras. Agradezco a dos revisores anónimos sus detalladas correcciones que han mejorado el texto. 


\section{Referencias}

Andrieux, J., Fontboté, J.M. \& Mattauer, M. (1971). Sur un modèle explicatif de l'Arc de Gibraltar. Earth and Planetary Science Letters, 12: 191-198. doi:10.1016/0012-821X(71)90077-X

Balanyá, J.C., Díaz-Azpiroz, M., Expósito, I, CrespoBlanc, A. \& Torcal, F. (2008). Asociaciones estructurales de la Alta Cadena (Béticas): un ejemplo de zona de cizalla frágil-dúctil con alto reparto de la deformación. Geo-Temas, 10: 317-320.

Barba Martín A., Martín Serrano A. y Piles Mateos E. 1979. Hoja geológica 1:50.000 no 1039 (Colmenar). I.G.M.E., 88 p.

Blumenthal, M. (1931). Géologie des chaînes pénibétiques et subbétiques entre Antequera et Loja et zones limitrophes (Andalousie). Bulletin de la Societé géologique de France, 5: 23-94.

Crespo-Blanc, A. 2008. Recess drawn by the internal zone outer boundary and oblique structures in the paleomargin-derived units (Subbetic Domain, central Betics): An analogue modelling approach. Journal of Structural Geology, 30, 65-80. doi:10.1016/j.jsg.2007.09.009

Delgado, F. \& Sanz de Galdeano, C. (1981). Estudio geológico de la Sierra del Gibalto y sectores próximos (provincias de Granada y Málaga). Estudios Geológicos, 37: 69-75.

Durand-Delga, M. \& Fontboté, J.M. (1980). Le cadre structural de la Méditerranée occidentale. 26 Congrès. Géol. Intern., Paris. Les Chaînes alpines issues de la Téthys. Mém. B.R.G.M., 115: 67-85.

García Dueñas, V. (1967). La Zona Subbética al Norte de Granada. PhD Thesis. Univ. de Granada.

García Dueñas, V. (1969). Les unités allochtones de la zone Subbétique dans la trasversale de Grenade (Cordillères Bétiques, Espagne). Revue de Géographie Physique et Géologie Dynamique, 11: 211-222.

Hermes, J.J. (1985). Algunos aspectos de la estructura de la Zona Subbética (Cordilleras Béticas, España Meridional). Estudios Geológicos, 41: 157-176. doi:10.3989/egeol.85413-4709

Magne, J., Peyre, Y., Del Valle, M. \& Vera J.A. (1969). La serie estratigráfica del Gallo-Vilo (prov. de Málaga). Acta Geológica Hispánica, 4: 67-71.

Martín-Algarra, A. (1987). Evolución geológica alpina del contacto entre las Zonas Internas y las Zonas
Externas de la Cordillera Bética. PhD Thesis. Univ. de Granada, $1171 \mathrm{pp}$.

Pérez-López, A. \& Sanz de Galdeano, C. (1994). Tectónica de los materiales triásicos en el sector central de la Zona Subbética (Cordillera Bética). Revista de la Sociedad Geológica de España, 7: 141-153.

Peyre, Y. (1974). Géologie d'Antequera et de sa région (Cordillères bétiques, Espagne). Lab. Géol. Méditerranéenne, PhD Thesis, Univ. de Paris, 518 pp.

Pineda, A. (1983). Mapa geológico de España, 1:50.000, hoja $\mathrm{n}^{\mathrm{o}} 1024$ (Archidona). I.G.M.E., Madrid.

Pineda Velasco, A. (1987). Sobre la geología de la región de Archidona y la pertenencia de la Alta Cadena al Subbético. Studia Geologica Salmanticensia, 24: 67-81.

Sanz de Galdeano, C. (1990). Geologic evolution of the Betic Cordilleras in the Western Mediterranean, Miocene to the present. Tectonophysics, 172: 107-119. doi:10.1016/0040-1951(90)90062-D

Sanz de Galdeano, C. (1996). The E-W segments of the contact between the External and Internal Zones of the Betic and Rif Cordilleras and the E-W corridors of the Internal Zone (A combined explanation). Estudios Geológicos, 52: 123-136. doi:10.3989/egeol.96523-4260

Sanz de Galdeano, C., Lozano, J.A. \& Puga, E. (2008). El "Trías de Antequera": naturaleza, origen y estructura. Revista de la Sociedad Geológica de España, 21: 110-124.

Sanz de Galdeano, C. \& Vera, J.A. (1992). Stratigraphic record and palaeogeographical context of the Neogene basins in the Betic Cordillera, Spain. Basin Research, 4: 21-36. doi:10.1111/j.1365-2117.1992.tb00040.x

Serrano, F. \& Guerra-Merchán, A. (2004). Geología de la provincia de Málaga. Diputación de Málaga, 294 pp.

Vera, J.A. (1969). Estudio geológico de la zona Subbética en la transversal de Loja y sectores adyacentes. Memorias del Instituto Geológico y Minero de España, 72, $187 \mathrm{pp}$.

Wildi, W. (1983). La chaîne tello-rifaine (Algérie, Maroc, Tunisie): structure, stratigraphie et évolution du Trias au Miocène. Revue de Géologie Dynamique et de Géographie Physique, 24: 201-297.

Recibido el 6 de noviembre de 2010 Aceptado el 21 de marzo de 2011 Publicado online el 7 de septiembre de 2011 